\title{
Structuring of nanomodified concrete cured in different temperature and humidity conditions
}

\author{
Viktor Voronin ${ }^{1 *}$ and Yuriy Bobrov \\ ${ }^{1}$ Moscow State University of Civil Engineering, 129337, Yaroslavskoye Shosse 26, Moscow, Russia \\ ${ }^{2}$ National Research University Higher School of Economics, 20 Myasnitskaya Ulitsa Moscow, Russia
}

\begin{abstract}
The article deals with the issues on the influence of the curing conditions on the formation of structure and properties of the concrete with nanomodifiers. Mechanochemically activated waste generated by the production of mineral fertilizers was used as nanomodified additives. It was established that providing favorable conditions for the initial structuring of concrete was the purpose of erecting structures made of concrete mix with said nanomodified additives in different temperature and humidity environments. It is provided that different types of production waste gaining the properties of efficient additives for binders, concrete mixes and compositions made on their basis as the result of the corresponding processing will be used as mineral fillers. Production waste is generally characterized by a heterogeneous composition and structure, by impurity content and by low chemical activity. Thus, one of the methods for increasing the efficiency of the waste is mechanical, chemical or physical activation. As the result of such activation, nanosizeparticles appear, and additional defects of mineral lattices are generated, which leads to accelerating the elementary interaction of the surface layer particles. Data on the research of macro- and microstructure of concrete and composites with nanomodifiers cured in different temperature and humidity conditions is given in the table.
\end{abstract}

\section{Introduction}

In accordance with the construction standards and regulations, the following three main climatic regions are identified: cold, moderate and hot [4]. The cold region is characterized by the average monthly temperature of below minus $15^{\circ} \mathrm{C}$.

The moderate region is characterized by the average monthly temperature between minus $15^{\circ} \mathrm{C}$ and minus $25^{\circ} \mathrm{C}$. On clear and windless days during the winter period, the atmospheric temperature in the central and southern Europe may go down to minus $35^{\circ} \mathrm{C}$, or, during the summer period, go up to plus $40^{\circ} \mathrm{C}$.

The hot climatic region has the longstanding average monthly temperature of plus $25^{\circ} \mathrm{C}$ in the hottest month. The curing of cement composites containing nanomodifieris due to the initial structuring has a significant influence on the concentration of new formations and on the development of porosity $[5,6]$.

\footnotetext{
*Corresponding author: tvvib@mgsu.ru
} 
Relatively small temperature fluctuations have a significant influence on the rate of curing of concrete as well.

For example, the relative strength at the age of 3 days will be $0.27 \mathrm{R} 28$ during concrete curing at $5^{\circ} \mathrm{C}$, and at $30^{\circ} \mathrm{C}$ at the same age, it will be $0.5 \mathrm{R} 28$, which is almost twice more.

The growtn rate of the indicator of concrete strength will gradually slowdown, and its ultimate strength will depend on the curing period when temperature changes take place.

So,if the cement composite containing a nanomodifier is cured at a changing temperature, then by certain age, its estimated strength will be determined as a sum of strengths obtained in the periods of curing at different temperatures:

$$
R c=\Delta R 1+\Delta R 2+\ldots+\Delta R n
$$

where $\Delta R 1, \Delta R 2, \ldots \Delta R n$ is change in the strength during temperature periods $t 1, t 2, t n$.

Providing favorable curing conditions, especially at an early age, when the future composite structure is formed, will have a positive influence on the concrete curing. It will not be possible to change a structure the formation of which was disturbed during an early period of curing, by providing favorable conditions in a subsequent curing period. Thus, the right curing of concrete during early periods of curing is a condition required for obtaining high-quality concrete containing nanomodifiers. It is known that the normal temperature for concrete curing is $15-20^{\circ} \mathrm{C}$. At a lower temperature, the concrete strength will increase more slowly than at a normal one.

An interrelation has been established between the curing temperature $(t)$ of the concrete and the period of structuring of the cement composite, which can be expressed as follows:

$$
T=20.1729-0.49837 t+0.00337 t 2
$$

The curing of the cement composite with a nanomodifier almost stops at the temperature below $0^{\circ} \mathrm{C}$. Frequent rises of temperature above $0^{\circ} \mathrm{C}$ will have a direct influence on the curing process. A composite frozen after being defrosted will keep hardening, and its strength will be increasing gradually.

Freezing of a cement composite with a nanomodifier at an early age may result in ice build-up accompanied by structure loosening [7]. The water density will be reduced in case of freezing. A porous low-density ice structure will be produced causing an increase in its volume and bond rupture between the filler surface and the cement stone. The strength of the cement composite with a nanomodifier is closer to the normal one, if it was frozen later. Table.5.1. and table 5.2. show the values of the critical strength, which must be reached by the composite before its freezing.

\begin{tabular}{|c|c|c|c|c|}
\hline \multirow[t]{2}{*}{$\begin{array}{l}\text { Freezing temperature } \\
{ }^{\circ} \mathrm{C}\end{array}$} & \multicolumn{2}{|c|}{$\begin{array}{l}\text { On the basis of Belgorodsky } \\
\text { cement and crushed } \\
\text { limestone }\end{array}$} & \multicolumn{2}{|c|}{$\begin{array}{l}\text { On the basis of } \\
\text { Voskresensky cement and } \\
\text { granite crushed stone }\end{array}$} \\
\hline & $\mathrm{MPa}$ & $\%$ & $\mathrm{MPa}$ & $\%$ \\
\hline-20 & 27.9 & 77 & 16.9 & 82 \\
\hline-10 & 26.9 & 75 & 16.4 & 80 \\
\hline-5 & 23.3 & 62 & 12.9 & 62 \\
\hline-2 & 20.1 & 56 & - & - \\
\hline Normal curing & 35.9 & 100 & 20.6 & 100 \\
\hline
\end{tabular}

Table 1. The strength of cement composites with a nanomodifier after freezing

Table 2.shows the values of the critical strength which must be reached by the composite before freezing without loss of quality. 
Reduced strength of the nanomodified concrete is related to the deformations caused by the occurrence of plastic shrinkage, processes of mass exchange and mass transfer, and contractions. Disturbance of the concrete structure during a short-term curing before freezing will reduce its frost resistance and impermeability. The frost resistance coefficient of the concrete with nanomodifiers turned out to be lower than the reference one $[8,9,10]$.

Table 2. Minimum strength which must be gained by the cement composite with a nanomodifier by the moment of freezing

\begin{tabular}{|c|c|c|c|}
\hline \multirow{2}{*}{$\mathrm{R}_{28}, \mathrm{MPa}$} & \multicolumn{2}{|c|}{ Minimum strength, no less than } & $\begin{array}{l}\text { Time o curing of the } \\
\text { composite at 15- 20 } \\
\text { o C, day }\end{array}$ \\
\cline { 2 - 4 } & $\%$ of $\mathrm{R}_{28}$ & $\mathrm{MPa}$ & $5 \ldots 7$ \\
\hline 10 & 50 & 5 & $3 \ldots 5$ \\
\hline 20 & 40 & 7 & $2 \ldots 2.5$ \\
\hline 30 & 35 & 10 & $1.5 \ldots 2$ \\
\hline 40 & 30 & 12 & $1 \ldots 2$ \\
\hline 50 & 25 & 12.5 & \\
\hline
\end{tabular}

\section{Conclusion}

The research carried out shows the extreme importance of providing favorable conditions for the curing of concrete with nanomodifiers at an early age, when it is being structured.

It is confirmed by the data obtained when testing concrete curing during $2.5-3 \mathrm{~h}$ in unfavorable conditions, and then, 28 days in normal conditions; its strength was reduced by $30-50 \%$, and the frost resistance and the impermeability were considerably reduced as well.

\section{References}

1. Yu.M. Bazhenov, L.A. Alimov, V.V. Voronin, Structure and properties of concrete with nanomodifiers on the basis of technogenic waste (Nomografiya, EBS ASV, 2013)

2. L.A. Alimov., V.V. Voronin, Building materials (Textbook. Publishing center, Academiya, 2012)

3. Yu.M. Bazhenov, Compilation of roundtable presentations, 12-18 (MGSU, 2007)

4. SNiP 23.01.99. Construction climatology

5. L.A. Alimov, V.V. Voronin, Concrete work technology (Textbook, Publishing center, Academiya, 2015)

6. L.A. Alimov, V.V. Voronin, A.A. Buldyzhov, I.V. Romanov, Mag. Nauchnoe obozrenie, 9, 177-181, (2013)

7. L.A. Alimov, V.V. Voronin, K.S. Stenechkina, O.V. Aleksandrova, Mag. PGS, 4, 58$61(2015)$

8. L.A. Alimov, S.I. Bazhenova, Vestnik MGSU, 1 (2010)

9. M.T. Bassuoni, M.M. Rahman, Orig. Res. Ar. Cem. and Conc. Res., 79, 395-408, (2016)

10. J.J. Gaitero, I. Campillo, A. Guerrero, Orig. Res. Ar. Cem. and Conc. Res., 38, $1112-$ $1118(2008)$

11. A.S. Inozemtcev, IOP Conference Series: Materials Science and Engineering, $\mathbf{7 1}$ (2015)

12. M.G. Bruyako, L.S. Grigoryeva, D.V. Kravtsova, Adv. Mat. Res., 860-863, 1323 $1326(2014)$ 
13. A. Adamtsevich, A. Pustovgar, S. Pashkevich, A. Eremin, A. Zhuravlev, App. Mech. and Mat., 670-671, 339-343 (2014) 